\title{
American College of Radiation Oncology (ACRO)
}

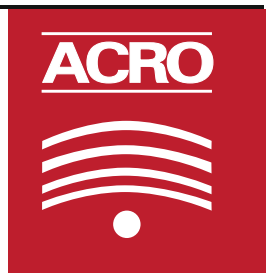

Published online: 22 May 2014

(C) Springer-Verlag Berlin Heidelberg 2014

The American College of Radiation Oncology (ACRO) is pleased to be able to call JRO its 'official journal' and to provide a subscription as one of many benefits of membership in the College. ACRO strives to ensure the highest quality care for radiation therapy patients and promote success in the practice of radiation oncology through education, responsible socioeconomic advocacy, and integration of science and technology into clinical practice. Membership is open to all radiation oncologists throughout the world, and colleagues who read this journal are invited to join the College and submit abstracts for the annual conferences, which are subsequently published in JRO. For more information go to www.acro.org.

This page is reserved for news and views from the American College of Radiation Oncology. The Editor of this page is A. Robert Kagan, MD, FACRO, a past president of the College and the long-time editor of The Bulletin, ACRO's quarterly Newsletter that ceased publication in 2012.

Note: The views expressed in the following editorial are not necessarily those of the American College of Radiation Oncology.

\section{Ethics and proton beam therapy}

\section{A. Robert Kagan \\ kaganmd@aol.com}

Clarifying the benefits of proton therapy by fancy is easy, but to clarify with hard evidence for a strong increased survival and decreased toxicity over photons is unavailable. At the present time, the dosimetric advantages of protons on paper are outweighed by its uncertainties, when applied to the patient. In the meantime, radiation oncologists are impatient to buy machines. There is little doubt that proton beam therapy is the most exciting thing to happen to radiation oncology since IMRT in the 1990s or computerized planning in the 1970s. Notably, however, proton beam therapy has failed its first test: lack of superiority over IMRT in prostate cancer. Physicians confronted with this negative evidence seem uninterested, proceeding ahead like a speeding train refusing to stop, continuing to buy proton machines, resisting any notion of doubt.

With the clinical evidence of the near 100,000 "proton" patients treated so far being "inconclusive", how does one explain the sudden explosion of the frantic desire to own a machine? The spokespersons for proton beam therapy, like the Crusaders, say it is the ethical thing to do, which I take to mean the best treatment for the patient. Science, when I last looked, depended on measurements not morality!

One of the four tenets of the ethics of medicine is the right of the patient to chose. If the physician suggests a single treatment is usually the best, that his recommendation is superior, that he is well experienced, and that his motivations are out of concern for the patient, how can a patient remain autonomous?

Regrettably, money is equal to medicine in proton beam economics. This exotic and expensive machine has, at many installations, been guaranteed by private investors similar to a hedge fund. Business ethics are very different from medical ethics. The ethic of business is to make as much money for the shareholders as possible. Business ethics is exclusively fiduciary, with no relation to people, except to be within the law.

When physicians allow economic self interest to be on an equal priority to that of patient care, they also become likely to employ the most costly interventions for clinical indications which are marginal. This practice means needless morbidity if the treatment was unnecessary. An ultimate result is a lack of belief in our professionalism by our community and country. 